\title{
Safety and Immunogenicity of a Genetically Engineered Human Immunodeficiency Virus Vaccine
}

\author{
Joëlle Wintsch, Claire-Lise Chaignat, \\ Dietmar G. Braun, Michel Jeannet, Hans Stalder, \\ Sergio Abrignani, Daniela Montagna, Freddy Clavijo, \\ Philippe Moret, Jean-Michel Dayer, \\ Theophil Staehelin, Barbara Doe, \\ Kathelyn S. Steimer, Dino Dina, and André Cruchaud
}
Department of Medicine, University Hospital, Geneva, and Ciba-Geigy Ltd., Basel, Switzerland; Chiron Research Laboratories, Emeryville, California

A phase 1 trial of a candidate human immunodeficiency virus type 1 (HIV-1) vaccine was done in 25 healthy seronegative subjects. The antigen, env2-3 (SF2), was a nonglycosylated polypeptide representing the gp120 region of the env gene of the HIV-1(SF2) isolate. It was produced in genetically engineered yeast as a denatured molecule incapable of binding CD4. A synthetic lipophilic muramyl tripeptide (MTP-PE) was used as an adjuvant. Ten subjects received adjuvant alone and 15 received 50- or 250- $\mu$ g doses of $e n v 2-3$ (SF2) administered intramuscularly in two immunization regimens. In general, adjuvant and vaccine were well tolerated. Antibody responses to both the homologous antigen, env2-3 (SF2), and antigens from other highly divergent HIV isolates were elicited in the majority of vaccine recipients. However, antibody titers were low, without neutralizing activity. In 9 of 11 subjects who received the complete vaccine immunization series, a significant specific $T$ lymphocyte response was observed.

Various experimental approaches have been proposed for the development of a vaccine against the human immunodeficiency virus type 1 (HIV-1) [1-4]. A killed, inactivated, or attenuated HIV vaccine antigen has the advantage of being nearly identical to the native virus [1] but is potentially hazardous to produce in large quantities and raises fear of the presence of infectious particles. Genetically modified vaccinia virus containing the envelope protein present on the surface of HIV has been used to vaccinate chimpanzees and humans [5-8]. Recently, an engineered poliovirus chimera eliciting broadly reactive HIV-1 neutralizing antibodies in rabbits has been described [9]. An alternative strategy that uses purified viral proteins or subunits produced by recombinant DNA methods offers significant manufacturing and safety advantages. Most notably, these vaccines are noninfectious and have no potential for transmitting disease.

\footnotetext{
Received 26 March 1990; revised 7 August 1990.

Informed consent was obtained from all subjects in this study, and human experimentation guidelines of Geneva University Hospital were followed; the study protocol was approved by the Ethical Committee on Clinical Investigations of the Department of Medicine, Geneva University Hospital.

Presented in part: International Symposium on Biomedical Research Strategy on AIDS (Yverdon-les-Bains, Switzerland, September 1989); annual meeting of the National Cooperative Vaccine Development Groups for AIDS (Fort Lauderdale, FL, October 1989).

Financial support: California Department of Public Health, National Institutes of Health (AI-22778), and Biocine.

Reprints or correspondence: Prof. André Cruchaud, Division of Immunology and Allergy, University Hospital, 1211 Geneva 4, Switzerland.

The Journal of Infectious Diseases 1991;163:219-225 (C) 1991 by The University of Chicago. All rights reserved. $0022-1899 / 91 / 6302-0001 \$ 01.00$
}

Our clinical trial was designed to study the safety and immunogenicity of env2-3 (SF2) antigen combined with the muramyl tripeptide-dipalmitoyl phosphatidylethanolamine (MTP-PE) adjuvant as a subunit HIV-1 vaccine in human subjects. Env2-3 (SF2) is a denatured, nonglycosylated polypeptide analog of HIV-1 gp1 20 produced in genetically engineered yeast cells. The external glycoprotein of HIV is pivotal in the binding of the virus to susceptible cells and the formation of syncytia in tissue culture systems [10-15]. In addition, affinity columns prepared with env2-3 (SF2) linked to Sepharose are able to bind antibodies from HIV-seropositive human sera, which, when eluted from the column, can neutralize several isolates of HIV-1 [16]. In preclinical studies, various species of animals immunized with env2-3 (SF2) produced antibodies capable of neutralizing the homologous virus isolate in vitro [17]. Similar results have been reported by others using genetically engineered [18] or virus-derived gp120 [19]. Env23 (SF2) does not bind to CD4, thus minimizing concerns about its potential immunosuppressive effects due to interference with T cell responses [20]. MTP-PE enhances antibody levels in an manner equivalent to complete Freund's adjuvant in various experimental animals [21]. The observed responses were much higher than those obtained with alum.

\section{Methods}

Volunteers. Twenty-five healthy men aged $20-60$, with no past or present risk for HIV infection, were enrolled. Their health status was assessed by a complete medical history, physical examination, hematology, blood chemistry, and urine analyses. Exclusion criteria included allergies, asthma of unknown cause, immune suppression of any kind, chronic debilitating viral infections, cancer, autoim- 
mune disease, and seropositivity for HIV or surface antigen of hepatitis B virus (HBsAg). All subjects were advised not to engage in any risk activity for HIV infection. They were given a certificate documenting their participation in the study.

Vaccine. Env2-3 (SF2) is a nonglycosylated polypeptide equivalent of the gp120 envelope glycoprotein of the HIV-1 SF2 isolate [22, 23] produced in the genetically engineered yeast Saccharomyces cerevisiae $[16,24]$. It has a molecular weight of $\sim 56,000$. The env23 (SF2) antigen was $>95 \%$ pure.

The adjuvant (MTP-PE) is a synthetic muramyl tripeptide covalently linked with dipalmitoyl phosphatidylethanolamine $[25,26]$. Squalene (Merck-Schuchardt, Darmstadt, FRG) and Tween 80 (ICI, Essen, FRG) were included in the adjuvant formulation [21]. The final vaccine preparation was obtained by emulsifying the antigen with the adjuvant formulation just before injection.

The study ran from August 1988 to September 1989. The trial was designed to be a randomized, open-label comparison of two immunization schemes: with adjuvant alone $(100 \mu \mathrm{g} / \mathrm{injection})$ or with a low ( $50 \mu \mathrm{g} /$ injection) or a high dose ( $250 \mu \mathrm{g} /$ injection) of $e n v 2-3$ (SF2) in the same adjuvant. Injections were administered alternately in the right and left deltoid muscles. Controls were injected with $100 \mu \mathrm{g}$ of MTP-PE alone at 0, 4, and 24 weeks (group 1) or 0, 4, $8,12,16$, and 20 weeks (group 2). The three remaining groups received $100 \mu \mathrm{g}$ of MTP-PE combined with $50 \mu \mathrm{g}$ of env2-3 (SF2) at 0,4 , and 24 weeks (group 3), $250 \mu \mathrm{g}$ of $e n v 2-3$ (SF2) at 0,4 , and 24 weeks (group 4), or $250 \mu \mathrm{g}$ of env2-3 (SF2) at $0,4,8,12,16$, and 20 weeks (group 5).

Monitoring of side effects. All subjects were monitored for $1 \mathrm{~h}$ after injection and reexamined after $24 \mathrm{~h}$. They were asked to record their local and systemic reactions for $48 \mathrm{~h}$.

Laboratory investigations. Blood and urine specimens were obtained for screening before enrollment and before each injection during the study. Analysis included complete blood counts, serum chemistry evaluations, urinalysis, coagulation tests, lymphocyte subpopulation determination, quantitative immunoglobulin levels (IgG, IgA, IgM, IgE), and determination of autoantibodies to HBsAg and to nuclear, gastric, thyroid, smooth muscle, striated muscle, heart muscle, mitochondria, adrenal, and salivary gland antigens. Urinalysis and hematology were performed $24 \mathrm{~h}$ after each injection.

Recombinant HIV-1 antigens used for evaluation of immune responses. In addition to the env2-3 (SF2) antigen from HIV-1(SF2), equivalent molecules from two other HIV-1 isolates, HIV/HTLVIII $_{B}$ (human T lymphotropic virus type III $_{B}$ ) [27] and HIV(Zr6) [28], were used in serologic assays. These antigens were purified as described previously $[16,17,29]$. Fully glycosylated native gp 120 from HIV-1(SF2), referred to as gpl20 (SF2), which retains the ability to bind to $\mathrm{CD} 4$, was produced in genetically engineered $\mathrm{CHO}$ cells [30].

Antibody assays. The levels of antibodies to the immunizing antigen were determined by indirect ELISA [17, 31], as was their crossreactivity with env2-3 (SF2)-equivalent polypeptides from HIV(Zr6) and HIV/HTLV-III

The recombinant immunoblot assay (RIBA; Chiron, Emeryville, CA) HIV 216 strip analysis and the Biotech/Du Pont HIV Western blot assay (New England Nuclear, Boston) were performed as described in the manufacturers' protocols.

Sera were tested for neutralization of HIV-1(SF2) as described previously $[16,17]$.
Peripheral blood mononuclear cell (PBMC) proliferation. Lymphoproliferative assays to detect mitogen and antigen-specific proliferation were performed following standard protocols [32]. PBMC recovered from ficoll-hypaque were cultured at $10^{5} /$ well $(0.2$ $\mathrm{ml} /$ well) in 96-well flat-bottom Costar microplates with $1 \mu \mathrm{g} / \mathrm{ml} \mathrm{mito-}$ gen, phytohemagglutinin (PHA; Wellcome, Dartford, UK), or 1, 3 , and $10 \mu \mathrm{g} / \mathrm{ml} e n v 2-3$ (SF2) or gpl20 (SF2) antigens. Cell proliferation was monitored by $\left[{ }^{3} \mathrm{H}\right]$ thymidine uptake after 3 and 7 days for PHA and antigen, respectively. Data are expressed as geometric means of counts per minute of triplicate cultures. A stimulation index $>4$ was considered a positive response.

\section{Results}

\section{Tolerability}

Three volunteers were excluded after the first injection for study-unrelated abnormalities detected in baseline studies done earlier the same day: a group 3 subject with IgM paraproteinemia, a group 4 subject with familial idiopathic thrombocytopenia, and a group 5 subject with iron-deficiency anemia. Two volunteers experienced injection-related events that led to exclusion after the second administration: a group 1 subject who experienced vasovagal syncope and a group 4 subject with a local hypersensitivity reaction to the env2-3 (SF2) antigen (without MTP-PE) documented by intradermal challenge.

Of 25 total volunteers in adjuvant and vaccine groups, 19 experienced mild local pain lasting up to $24 \mathrm{~h}$ after at least one injection. Of the 15 who received the complete vaccine, $3 \mathrm{had}$ local induration of the skin that disappeared after 3-24 h.

Four of the same 15 subjects reported a significant sensation of fatigue lasting $<24 \mathrm{~h}$. Fatigue was not reported in the two control groups. Two volunteers in the vaccine groups had fever (axillary $38^{\circ} \mathrm{C}$ ), after one of their immunizations, that disappeared within 1 day. Four volunteers experienced a mild headache.

There was no alteration of hematologic, blood chemistry, or urinalysis values that proved to be study related. No autoantibodies were detected, and the levels of all four immunoglobulin classes remained stable, indicating the absence of polyclonal B lymphocyte stimulation. Relative and absolute CD4 and CD8 T cell values remained unchanged in all fully immunized subjects.

\section{Immunogenicity of the Vaccine}

For the serology and lymphoproliferative assays, we have included data only from individuals who completed the immunization series.

Antibody responses. Among the subjects receiving adjuvant alone, only 1 (subject 6) showed evidence of a signal above background on ELISA. The antibody titer did not increase with repeated doses of adjuvant. Seroconversion to env2-3 (SF2) occurred in 8 of the 11 volunteers who received the complete immunization series with vaccine. 
Table 1. Results of serologic assays of specimens obtained 1 month after the final dose of env2-3 (SF2).

\begin{tabular}{|c|c|c|c|c|c|}
\hline \multirow{2}{*}{$\begin{array}{l}\text { Group, } \\
\text { volunteer } \\
\text { no. } \\
\end{array}$} & \multirow[b]{2}{*}{ Western blot* } & \multirow[b]{2}{*}{ RIBA $^{\dagger}$} & \multicolumn{3}{|c|}{ ELISA titer $\$$} \\
\hline & & & env2-3 (SF2) & $e n v 2-3\left(\mathrm{III}_{\mathrm{B}}\right)$ & $e n v 2-3(\mathrm{Zr} 6)$ \\
\hline 3,12 & - & - & $<10$ & $<10$ & $<10$ \\
\hline 13 & - & - & $<10$ & $<10$ & $<10$ \\
\hline 14 & -. & \pm & 22 & $<10$ & $<10$ \\
\hline 15 & + & + & 293 & 155 & 192 \\
\hline 4,18 & - & - & $<10$ & $<10$ & $<10$ \\
\hline 19 & \pm & + & 38 & 38 & 62 \\
\hline 20 & - & - & 9 & $<10$ & $<10$ \\
\hline 5,21 & + & + & 227 & 222 & 275 \\
\hline 22 & + & + & 66 & 74 & 58 \\
\hline 23 & \pm & + & 43 & 44 & 154 \\
\hline 25 & \pm & + & 46 & 22 & 44 \\
\hline
\end{tabular}

* Reactivity with the gp 120 band: + , strong; \pm , weak but visible.

† Chiron recombinant immunoblot assay HIV-216 strip analysis. Reaction was observed with the gp L20-equivalent band but not with any of the other antigens on the strip (gp41, p31, p24): + , strong; \pm , weak but visible.

$\ddagger$ In instances where a signal was observed with prevaccination sera, the preimmunization background titer was subtracted from the postimmunization values. This was necessary only in the env2-3 (III ${ }_{B}$ ) and env2-3 (Zr6) ELISAs, which used antigens that were less pure than the env2-3 (SF2) preparation. Sera with titers indicated as <10 showed no signal at 1:10 serum dilution, the most concentrated dilution tested.

Group 5 individuals showed the highest and most consistent anti-env2-3 (SF2) antibody responses 4 weeks after the last vaccination. However, the antibody titers were only $5 \%-$ $10 \%$ of those induced by natural infection. The env2-3 (SF2) ELISA titers of 86 serum specimens from HIV-seropositive individuals were $\sim 100-50,000$ (reciprocal dilution) with an average of 1500-2500 (data not shown).

Table 1 summarizes the results of additional serologic assays. The results of RIBA with sera collected 1 month after the final immunization provide an independent confirmation of seroconversion to env2-3 (SF2). Seven of the 8 volunteers showing evidence of $e n v 2-3$ (SF2) seroconversion on ELISA (but none of the volunteers injected with adjuvant alone) also reacted with the gp120-equivalent band on RIBA. Finally, sera from volunteers scoring positive with the gp120-equivalent band did not react with any other HIV antigens on RIBA (data not shown).

To test whether sera from volunteers immunized with env2-3 (SF2) cross-reacted with the fully glycosylated gp120, a Biotech/Du Pont Western blot assay with virus was done. Three volunteers had strong reactivity and three showed weak reactivity with viral gpl20 (table 1).

Since the virus used in the Western blot is HIV/HTLV$\mathrm{III}_{\mathrm{B}}$, these data suggest that reactivity elicited by env2-3 (SF2) is likely to be directed toward regions of gp120 that are conserved among multiple HIV-1 isolates. This hypothesis was supported by doing ELISA with env2-3 (SF2)-equivalent molecules from HIV/HTLV-III ${ }_{B}$ and HIV (Zr6), which differ from HIV-1(SF2) in $19 \%$ and $26 \%$, respectively, in the predicted amino acids of their gpl 20 polypeptides (see table 1). Cross-reactivity of all of the sera with high titers of anti- bodies to env2-3 (SF2) was observed with the equivalent molecules from these two isolates.

Finally, the sera from env2-3 (SF2)-immunized individuals did not neutralize HIV-1(SF2) virus in vitro.

Antigen-specific T cell proliferation. PBMC proliferative responses to various gpl20-derived antigens and to five env2-3 (SF2)-unrelated antigens (purified protein derivative, tetanus toxoid, streptococcal antigen preparation, Candida albicans antigen preparation, and irradiated allogenic cells) were monitored throughout the trial. The proliferative responses to PHA

Table 2. Antigen-specific peripheral blood mononuclear cell (PBMC) proliferation responses to HIV-1 recombinant envelope proteins.

\begin{tabular}{cccccc} 
& \multicolumn{5}{c}{ Group } \\
\cline { 2 - 5 } Weeks & $(n=4)$ & $(n=5)$ & $(n=4)$ & $(n=3)$ & $(n=4)$ \\
\hline 0 & 0 & 0 & 0 & 0 & 0 \\
4 & 0 & 1 & 1 & 0 & 0 \\
8 & 0 & 1 & 3 & 0 & 1 \\
12 & ND & 1 & 3 & 1 & 1 \\
16 & ND & 1 & 3 & 2 & 2 \\
20 & ND & 1 & 3 & 0 & 2 \\
24 & 0 & 0 & 3 & 1 & 3 \\
28 & 0 & ND & 4 & 2 & ND \\
32 & ND & ND & 4 & ND & ND \\
36 & ND & ND & 4 & 2 & ND \\
\hline
\end{tabular}

NOTE. ND, not determined. Data are number of subjects positive at number of weeks after start of trial. PBMC responses were assessed using env2-3 (SF2) only for groups 1 and 2 and both env2-3 (SF2) and gp120 (SF2) for groups 3-5. Numbers for the vaccine groups refer to responses to gp120 (SF2). Numbers of responses to env2-3 (SF2) were equivalent. 
Group 1

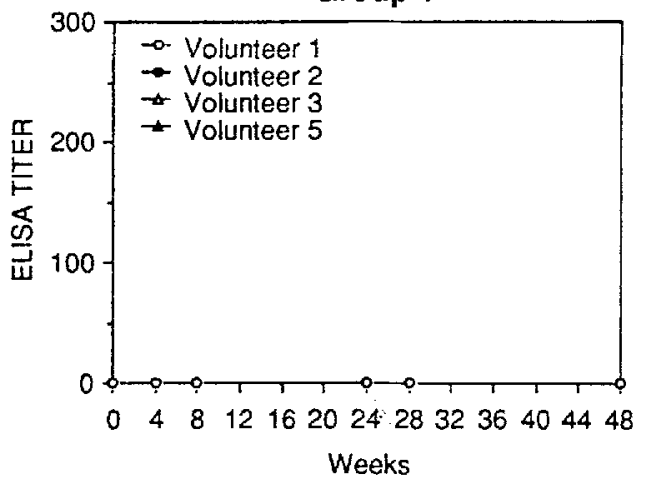

Group 3
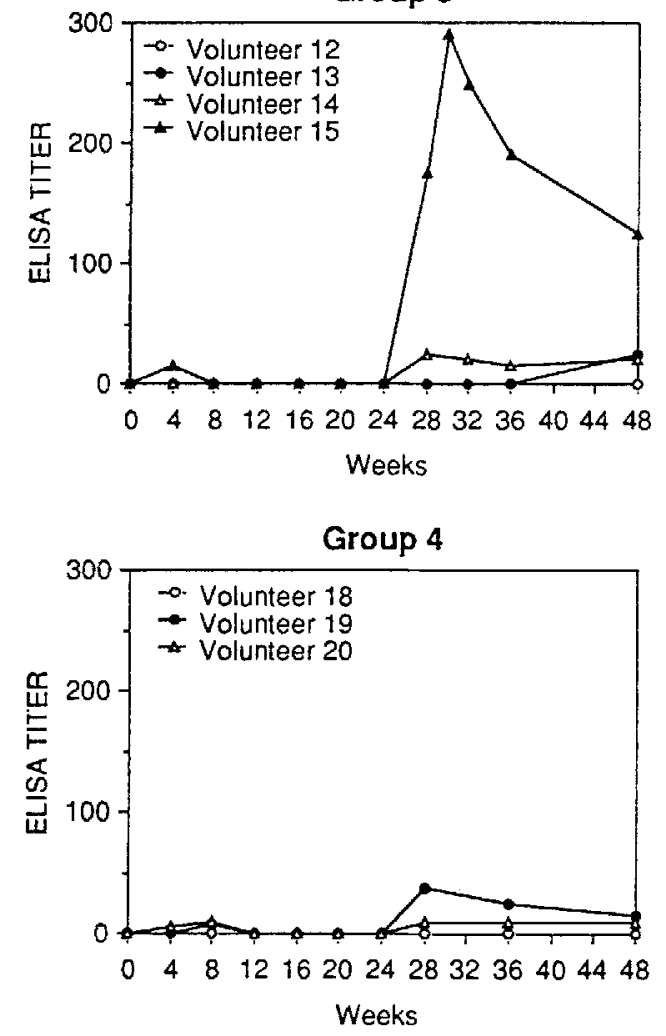

Group 2

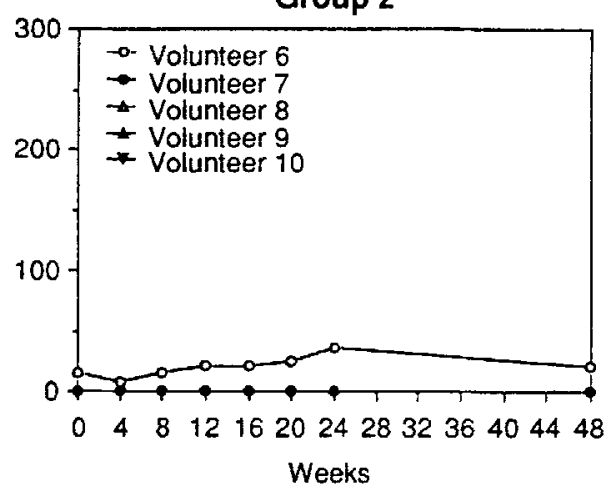

Group 5

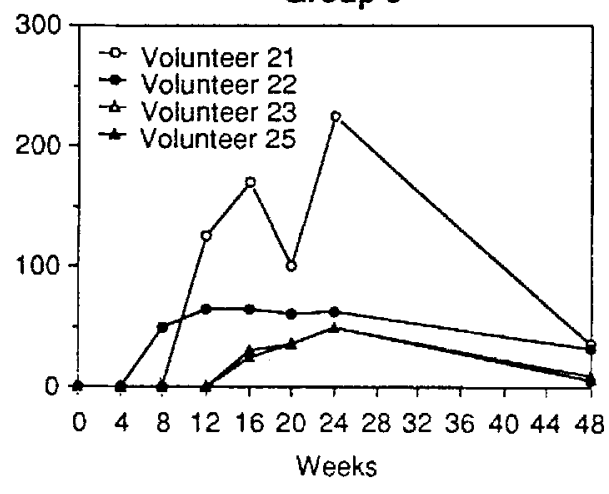

Figure 1. Titers of ELISA-reactive antibodies among trial volunteers. Tested sera were diluted 1:10 and by serial twofold dilutions for antibodies to env2-3 (SF2). For this assay, microtiter plates were coated with $2 \mu \mathrm{g} / \mathrm{ml} e n v 2-3(\mathrm{SF})$. The assay protocol has been described previously $[16,17,31]$. Titers reported correspond to the reciprocal of the dilution that resulted in an ELISA signal equivalent to half the maximum value obtained in the assay. The maximum value was typically $\mathrm{OD}=1.2$. Each sample was assayed in duplicate and the average shown. and to these five control antigens remained unchanged throughout the study in all subjects of all groups (data not shown). The proliferative responses to env2-3 (SF2) throughout the study are shown in table 2 . Preimmunization $T$ cell proliferative responses to env2-3 (SF2) were not detected in either the controls or vaccine recipients. After immunization, the four subjects of group 3 (three injections of the low-dose vaccine) developed a $\mathrm{T}$ cell proliferative response to env2-3 (SF2), whereas only two of three subjects in group 4 and three of four in group 5 responded, although they had received the high dose of vaccine. Also, in the latter two groups, response occurred later than in group 3.

Surprisingly, the PBMC of subject 6 (group 2, control) significantly responded to env2-3 (SF2) from week 4 up to week 20 but appeared nonreactive at week 24 . Very low antibody titers were also detected in the sera of this subject (figure 1). However, the polymerase chain reaction done 1 year after the start of study was negative in this subject, suggesting that serologic and cellular reactions were nonspecific, as has been reported for serologic testing [33]. This might be due to crossreactivity with other microorganisms or to particular physicochemical properties of plasma proteins. The PBMC responses of all other controls remained unreactive during the entire trial period.

In every case where env2-3 (SF2)-specific proliferation was observed in individuals receiving vaccine (table 2 ), it was also 
Table 3. Specific peripheral blood mononuclear cell (PBMC) responses measured before the first injection and 4 weeks after the last boost.

\begin{tabular}{|c|c|c|c|c|}
\hline \multirow{2}{*}{$\begin{array}{l}\text { Group, } \\
\text { volunteer } \\
\text { no. }\end{array}$} & \multicolumn{2}{|c|}{ Week 0} & \multicolumn{2}{|c|}{ Week $24 / 28^{*}$} \\
\hline & Medium & env2-3 (SF2) & Medium & $e n v 2-3$ (SF2) \\
\hline \multicolumn{5}{|l|}{1 , control } \\
\hline 1 & 2.2 & 4.4 & 0.1 & 0.2 \\
\hline 2 & 3.5 & 4.5 & 0.1 & 0.1 \\
\hline 3 & 0.3 & 0.3 & 0.1 & 1.2 \\
\hline 5 & 0.1 & 0.3 & 0.9 & 0.8 \\
\hline \multicolumn{5}{|l|}{2 , control } \\
\hline 6 & 0.7 & 0.6 & 0.2 & 0.9 \\
\hline 7 & 0.8 & 0.7 & 0.1 & 0.4 \\
\hline 8 & 0.2 & 0.5 & 0.2 & 0.7 \\
\hline 9 & 0.4 & 0.4 & 0.3 & 0.6 \\
\hline \multirow[t]{2}{*}{10} & 0.3 & 0.3 & 0.7 & 0.8 \\
\hline & Medium & $\mathrm{gp} 120(\mathrm{SF} 2)$ & Medium & $\mathrm{gp} 120$ (SF2) \\
\hline \multicolumn{5}{|l|}{3, vaccine } \\
\hline 12 & 1.7 & 2.4 & 0.1 & $4.2 \quad(42)$ \\
\hline 13 & 4.3 & 4.4 & 0.2 & $4.4 \quad(22)$ \\
\hline 14 & 1.0 & 0.9 & 0.1 & $18.1(181)$ \\
\hline 15 & 1.6 & 1.7 & 0.1 & $15.5(155)$ \\
\hline \multicolumn{5}{|l|}{4 , vaccine } \\
\hline 18 & 0.9 & 1.2 & 0.6 & 22.2 \\
\hline 19 & 0.3 & 0.3 & 3.1 & $36.7 \quad(12)$ \\
\hline 20 & 0.1 & 0.2 & 1.7 & 1.2 \\
\hline \multicolumn{5}{|l|}{5 , vaccine } \\
\hline 21 & 0.1 & 0.1 & 0.2 & $2.0 \quad(10)$ \\
\hline 22 & 1.4 & 0.4 & 0.2 & $18.7 \quad(94)$ \\
\hline 23 & 0.4 & 0.8 & 2.1 & 2.5 \\
\hline 25 & 0.4 & 0.2 & 0.7 & 2.9 \\
\hline
\end{tabular}

NOTE. Data represent $\left[{ }^{3} \mathrm{H}\right]$ thymidine uptake $\left(\mathrm{cpm} \times 10^{-3}\right)$ of PBMC cultured for 7 days in the absence (medium) or in the presence of $3 \mu \mathrm{g} / \mathrm{ml}$ antigen env2-3 (SF2)/gp120 (SF2). Bold type indicates significant gp 120 (SF2) responses with stimulation indices in parentheses.

$* 28$ weeks for groups 1,3 , and $4 ; 24$ weeks for groups 2 and 5 .

observed when fully glycosylated native gp1 20 (SF2) was used (table 3).

\section{Discussion}

Clinically, the vaccine used in this phase I trial was well tolerated. The main side effect was minor, short-lived pain. Two volunteers were removed from the trial as a result of injection-related events: one after experiencing vasovagal syncope immediately after injection of adjuvant and another because of a local hypersensitivity reaction probably due to the antigen. There were no significant alterations in the results of routine laboratory testing. This study also revealed that MTP-PE at $100 \mu \mathrm{g}$ per intramuscular injection was well tolerated and caused no undesirable side effects [26, 34].

One of the major concerns about candidate AIDS vaccines that contain gp120 is the potential for causing impairment of $\mathrm{CD}^{+} \mathrm{T}$ cell function due to binding of gpl20 to CD4 recep- tors $[35,36]$. None of the volunteers who completed the immunization series exhibited cellular immunosuppression as measured by absolute CD4 and CD8 counts and CD4-to-CD8 ratios. In addition, repeated injections of adjuvant alone or the complete vaccine did not modify the baseline immunologic status of recipients. In particular, no autoimmune reactions were induced, hypergammaglobulinemia through polyclonal cell activation was not detected, and there were no alterations in peripheral blood lymphocyte subpopulations or changes in the cellular immune response to nonspecific mitogens, allogeneic cells, or environmental antigens.

Immunization resulted in seroconversion to env2-3 (SF2) in the majority of volunteers. Cross-reactivity with the fully glycosylated version of HIV-1 gpl 20 was seen in Western blot assays with sera from those individuals exhibiting the highest titers of antibodies to env2-3 (SF2). In addition, there was evidence that these antibodies cross-reacted with envelope antigens from highly divergent HIV-1 isolates. However, we did not observe any neutralization of HIV-1 infectivity. This was not surprising, as the antibody titers elicited against env2-3 (SF2) were very low. In fact, in comparison with our experience using experimental animals immunized with env2-3 (SF2), antibody titers in sera from vaccinees were well below the usual threshold at which neutralization of HIV-1(SF2) infectivity is observed in vitro.

In contrast to the antibody results, we obtained in part a strong cellular response in 9 of 11 vaccine recipients. The stimulation was more prominent among subjects who received the low dose of antigen with a rest period of 5 months before the second boost. The $\mathrm{T}$ cells involved in this response recognized not only the env2-3 (SF2) antigen but also the native glycosylated gpl20 (SF2). A detailed account of this study, including major histocompatibility complex restriction and the cross-reactivity of both PBMC and gpl20-specific T cell clones with envelope proteins from other HIV isolates, has been reported elsewhere [37].

The efficacy of a candidate HIV vaccine can be tested only in a prospective placebo-controlled clinical trial. Before such trials can be initiated, some indications about the protective potential of vaccine candidates must be obtained by using in vitro immunologic assays that are expected to correlate with in vivo protection. Neutralizing antibodies are thought to play a role in antiviral activity, but until recently they have not been shown to prevent infection of experimental animals with the HIV system [38]. The fact that rhesus monkeys are immune to the simian immunodeficiency virus after inoculation with a killed whole-virus vaccine points to the possible importance of humoral responses in protective immunity. In addition, the helper $\mathbf{T}$ cell responses generated by a soluble antigen may, on virus infection, play an important role complementing the antibodies present. Healthy HIV-seropositive individuals have been known to be depleted of helper $\mathrm{CD}^{+} \mathrm{T}$ cells capable of recognizing virus-specific antigens, including gp120 [39, 40]. In contrast, some seronegative individuals with HIV- 
infected partners have detectable levels of HIV-specific helper $T$ cells [41] indicating a possible role for this lymphocyte subset in protective immunity. An effective HIV vaccine may thus require both antigen-specific helper $T$ cell responses and the presence of antibodies with cross-neutralizing properties against epidemiologically prevalent HIV isolates.

\section{Acknowledgment}

We thank W. J. Rutter, J Nüesch, and J. Gelzer for advice and support; E. Tillson, B. Mendez, P. van Hoogevest, R. Bürk, and A. Peil for help in organization of the trial; C. Dekker for help and suggestions throughout the trial and for critical reading of the manuscript; Y. Kessler, N. Roch, and P. August for secretarial help.

\section{References}

1. Salk J. Prospects for the control of AIDS by immunizing seropositive individuals. Nature 1987;327:473-6.

2. Koff WC, Hoth DF. Development and testing of AIDS vaccines. Science 1988;241:426-32.

3. Zuckermann AJ. Prospects for vaccines against AIDS. BMJ 1988;297: 86-8.

4. Ada G. Prospects for a vaccine against HIV. Nature 1989;339:331-2.

5. Chakrabarti S, Robert-Guroff M, Wong-Staal F, Gallo RC, Moss B. Expression of the HTLV-III envelope gene by a recombinant vaccinia virus. Nature 1986;320:535-7.

6. Hu SL, Kosowski SG, Dalrymple JM. Expression of AIDS virus envelope gene in recombinant vaccinia viruses. Nature 1987;320:537-40.

7. Hu SL, Fultz PN, McClure HM, et al. Effect of immunization with a vaccinia-HIV env recombinant on HIV infection of chimpanzees. Nature 1987;328:721-3.

8. Zagury D, Bernard J, Cheynier R, et al. A group specific anamnestic immune reaction against HIV-1 induced by a candidate vaccine against AIDS. Nature 1988;332:728-31.

9. Evans DJ, McKeating J, Meredith JM, et al. An engineering poliovirus chimaera elicits broadly reactive HIV-1 neutralizing antibodies. Nature 1989-339:385-8.

10. Gelderblom HR, Hausmann, EHS, Oezel M, Pauli G, Koch MA. Fine structure of human immunodeficiency virus (HIV) and immunolocalization of structural proteins. Virology 1987;156:171-6.

11. Dalgleish AG, Beverly PCL, Clapham PR, Crawford DH, Greaves MF, Weiss RA. The CD4 (T4) antigen is an essential component of the receptor for the AIDS retrovirus. Nature 1984;312:763-7.

12. Klatzmann D, Champagne E, Chamaret S, et al. T-lymphocyte T4 mol ecule behaves as the receptor for human retrovirus LAV. Nature 1984;312:767-8.

13. McDougal JS, Kennedy MS, Sligh JM, Cort SP, Mawle A, Nicholson JKA. Binding of HTLV-III/LAV to $\mathrm{T}^{+} \mathrm{T}$ cells by a complex of the 11OK viral protein and the T4 molecule. Science 1985;231:382-5.

14. Lifson JD, Feinberg MB, Reyes GR, et al. Induction of CD4-dependent cell fusion by the HTLV-III/LAV envelope glycoprotein. Nature 1986;323:725-8.

15. Fung MSC, Sun C, Sun NC, Chang NT, Chang W. Monoclonal antibodies that neutralize HIV-1 virus and inhibit syncytium formation by infected cells. Biotechnology 1987;5:940-6.

16. Steimer KS, Van Nest G, Haigwood NL, et al. Recombinant env and gag polypeptides in characterizing HIV-1-neutralizing antibodies. In: Ginsberg H, Brown F, Lerner RA, Chanock RM, eds. Vaccines '88. Cold Spring Harbor, NY: Cold Spring Harbor Press, 1988:347-55.
17. Steimer KS, Van Nest G, Dina D, Barr PJ, Luciw PA, Miller ET. Genetically engineered human immunodeficiency envelope glycoprotein gpl 20 produced in yeast is the target of neutralizing antibodies, In: Ginsberg H, Brown F, Lerner RA, Chanock RM, eds, Vaccines 87 Cold Spring Harbor, NY: Cold Spring Harbor Press, 1987:236-41.

18. Weiss R, Clapham P, Weber J, Dalgleish A, Laskey L, Berman P. Variable and conserved neutralization antigens of human immunodeficiency virus. Nature 1986;324:572-5.

19. Nara PL, Robey WG, Pyle SW, et al. Purified envelope glycoproteins from human immunodeficiency virus type 1 variants induce individual, type-specific neutralizing antibodies. J Virol 1988;62:2622-8.

20. Krowka J, Stites D, Mills J, et al. Effects of interleukin 2 and large envelope glycoprotein (gpl20) of human immunodeficiency virus (HIV) on lymphocyte proliferative responses to cytomegalovirus. Clin Exp Immunol 1988;72:179-85.

21. Sanchez-Pescador L, Burke RL, Ott G, Van Nest G. The effect of adjuvant on the efficacy of a recombinant herpes simplex virus glycoprotein vaccine. J Immunol 1988;141:1720-7.

22. Levy JA, Hoffman AD, Kramer SM, Laudis JA, Shimabukuro JM, Oshiro LS. Isolation of lymphocytopathic retrovirus from San Francisco patients with AIDS. Science 1984;225:840-1.

23. Sanchez-Pescador R, Power MD, Barr PJ, et al. Nucleotide sequence and expression of an AIDS-associated retrovirus (ARV-2). Science 1985;227:484-92.

24. Barr PJ, Parkes D, Sabin EA, et al. Expression of functional domains of the AIDS associated retrovirus (ARV) in recombinant microorganisms. UCLA Symposium on Molecular Cell Biology, New Series 1987;43:205-19.

25. Gisler RH, Schumann G, Sackmann W, Pericin C, Tarcsay L, Dietrich FM. A novel muramyl peptide, MTP-PE: profile of biological activities. In: Yamamura Y, Kotani S, Azuma L, Koda A, Shiba T, eds. Immunomodulation by microbial products and related synthetic compounds. Princeton, NJ: Excerpta Medica, 1982:167-170.

26. Schumann $G$, van Hoogevest $P$, Fankhauser $P$, et al. Comparison of free and liposomal MTP-PE: pharmacological, toxicological and pharmacokinetic aspects. In: Lopez-Berestein G, Fidler IJ, eds. Liposomes in the therapy of infectious diseases and cancer. New York: AR Liss, 1989:191-203.

27. Ratner L, Haseltine W, Patarca R, et al. Complete nucleotide sequence of the AIDS virus, HTLV-III. Nature 1985;313:277-84.

28. Srinivasan A, Anand R, York D, et al. Molecular characterization of human immunodeficiency virus from Zaire: nucleotide sequence analysis identifies conserved and variable domains in the envelope gene. Gene 1987;52:71-82.

29. Barr PJ, Steimer KS, Sabin EA, et al. Antigenicity and immunogenicity of domains of the human immunodeficiency virus (HIV) envelope polypeptide expressed in the yeast Saccharomyces cerevisiae. Vaccine 1987;5:90-101.

30. Haigwood NL, Barker CB, Higgins KW, et al. Evidence for neutralizing antibodies directed against conformational epitopes of HIV-1 gpl20. In: Brown F, Chanock, R, Ginsberg H, Lerner R, eds. Vaccines ' 90. Cold Spring Harbor, NY: Cold Spring Harbor Press, 1990:313-20.

31. Steimer KS, Higgins KW, Powers MA, et al. Recombinant polypeptide from the endonuclease region of the acquired immune deficiency syndrome retrovirus polymerase $(\mathrm{pol})$ gene detects serum antibodies in most infected individuals. J Virol 1986;58:9-16.

32. Cunningham-Rundels S, Hansen JA, Dupont B. Lymphocyte transformation to mitogens and antigens. In: Bach F, Good RA, eds. Clinical immunology. New York: Academic Press, 1976:151-94.

33. Centers for Disease Control. Update: serologic testing for antibody to human immunodeficiency virus. MMWR 1988;36:833-45.

34. Braun DG, Dukor P, Lukas B, et al. MTP-PE, a synthetic lipophilic muramylpeptide: biological and toxicological properties. In: Berlin 
A, Dean J, Draper MH, Smith EMB, Spreafico F, eds. Immunotoxicology. Boston: M Nijhoff, 1987:219-233.

35. Mann DL, Lasane F, Popovic M, et al. HTLV-III large envelope protein (gp120) suppresses PHA-induced blastogenesis. J Immunol 1987; 138:2640-4.

36. Bank I, Chess L. Perturbation of the T4 molecule transmits a negative signal to T cells. J Exp Med 1985;162:1294-303.

37. Abrignani $S$, Montagna $\mathrm{D}$, Jeannet $\mathrm{M}$, et al. Priming of $\mathrm{CD} 4^{+} \mathrm{T}$ cells specific for conserved regions of human immunodeficiency virus glycoprotein gp120 in humans immunized with a recombinant envelope protein. Proc Natl Acad Sci USA 1990;87:6136-40.

38. Desrosiers RC, Wyand MS, Kodama T, et al. Vaccine protection against simian immunodeficiency virus infection. Proc Natl Acad Sci USA 1989;86:6353-7.

39. Gurley RJ, Ikeuchi K, Byrn RA, Anderson K, Groopman JE. Lymphocyte function with early human immunodeficiency virus infection. Proc Natl Acad Sci USA 1989;86:1993-7.

40. Krowka JF, Stites DP, Jain S, et al. Lymphocyte proliferative responses to human immunodeficiency virus antigens in vitro. J Clin Invest 1989;83:1198-203.

41. Ranki A, Mattinen S, Yarchoan R, et al. T-cell response towards HIV in infected individuals with and without zidovudine therapy, and in HIV-exposed sexual partners. AIDS 1989;3:63-9. 